\title{
EFFICACY OF AUTOLOGOUS LEUCOCYTE-PLATELET-RICH FIBRIN (L-PRF) VERSUS HYDROXYAPATITE AS A GRAFT MATERIAL FOR SOCKET HEALING AFTER SURGICAL EXTRACTION OF IMPACTED MANDIBULAR THIRD MOLARS: A COMPARATIVE CLINICAL AND RADIOGRAPHIC STUDY
}

\author{
Sayed A. Rashed*, Ahmed T. Elsharkawy**, Amira Zaied ${ }^{* * *}$ and Ali Fahd****
}

\begin{abstract}
OBJECTIVE: The purpose of this study was to compare the efficacy of Leucocyte -platelet-rich fibrin (L-PRF), and hydroxyapatite (HA) for reduction of pain and swelling, the incidence of dry socket, soft tissue healing, and bone regeneration after surgical removal of impacted mandibular third molar in human patients.
\end{abstract}

Patients and Methods: Thirty-six patients (20 males and 16 females) requiring extraction of mandibular third molars were randomly grouped as L-PRF, HA, and Control-treated. All the procedures were done on an outpatient basis without any complication such as lip numbness. The patients were assessed for postoperative pain, swelling and maximal inter-incisal distance on the 1st, 3rd and 7th postoperative days. Exposed bony socket wall (dry socket), as well as soft tissue healing (healthy granulation tissue Formation), were also assessed at 1st, 3rd, 7th and 14th day of postoperative periods depending on the standard methods. Assessment of daily and total analgesics consumption was done and Radiological assessment of the extraction site was done at 2 and 6 months interval.

Results: Pain, swelling, interincisal distance, and soft tissue healing had statistically significant more improvement for L-PRF group compared to HA and control groups. Radiographic assessment showed comparatively lesser bone density values in PRF and control sites at 2 and 6 months than HA site.

Conclusion: Our study showed that L-PRF is better graft materials than HA regarding pain, swelling, dry socket, and soft tissue healing post-L-PRF placement in the extraction socket. Bone regeneration is induced quickly by HA as compared to PRF. However, study with a wide scale of clinical cases is very much essential to be more decisive regarding the efficacy of the graft materials.

KEYWORDS: Platelet-rich fibrin, L-PRF, Bone density, hydroxyapatite, mandibular third molar surgical removal.

\footnotetext{
* Lecturer, Department of Oral and Maxillofacial Surgery, Faculty of Dentistry, Ahram Canadian University.

** Lecturer, Department of Oral and Maxillofacial Surgery, Faculty of Dentistry, Cairo University.

***Lecturer, Department of Oral and Maxillofacial Surgery, Faculty of Dentistry, Fayoum University.

****Lecturer, Department of Oral and Maxillofacial Radiology, Faculty of Dentistry, Ahram Canadian University.
} 


\section{INTRODUCTION}

The healing process is a normal biochemical, mechanical, cellular and molecular response of the body in order to restore the tissue integrity. Events of the normal wound healing could take place in three overlapping phases: inflammatory, proliferative, and remodeling phase. Several platelets concentrates have been utilized to optimize wound healing; like platelet-rich plasma (PRP) and platelet-rich fibrin (L-PRF). It is assumed that leucocytes and platelet-rich fibrin (L-PRF) is a second generation of (PRP) where autologous platelets and leucocytes in a complex fibrin matrix accelerate the healing of soft and hard tissue benefiting from their biological characteristics with the effect of various growth factors. ${ }^{(1-6)}$

L-PRF has been utilized in regenerative dentistry as a supra-physiological concentrate of growth factors capable of stimulating tissue regeneration without the use of anti-coagulants known to inhibit wound healing. PRF has a fibrin network structure, platelets, white blood cells, growth factors, and cytokines which is helpful for tissue repair. These growth factors include platelet-derived growth factor, epithelial growth factor, transforming growth factors- $\beta$, vascular endothelial growth factor and interleukin-1,4 and 6 . These components can be effective in regulating the proliferation, differentiation, and apoptosis of cells and promoting tissue repair. In view of the biological characteristics, PRF is safe, effective and more economical as a graft material for alveolar sites. ${ }^{(7-11)}$

However, the use of platelet-rich fibrin (PRF) as graft material has increased in recent years. The beneficial growth factors from platelets were first described by Ross et al. ${ }^{(12)}$ Choukroun ${ }^{(13)}$ defined PRF as a fibrin matrix in which platelet cytokines and cells are trapped and could serve as a graft material. More recently, L-PRF is presented to be a suitable scaffold for breeding human periosteal cells in vitro, thus also being valuable for bone tissue engineering applications. ${ }^{(14-15)}$
Several biocompatible materials have developed as substitutes of autologous bone. Among synthetic biomaterials, hydroxyapatite (HA), the bioglass and bioceramics are also widely accepted. The unique chemical similarity of HA with the mineralized phase of bone makes it osteoconductive and biocompatible. It is widely used in dental, craniofacial, and orthopedic surgery. ${ }^{(16-18)}$

On the light of the above information, this study was conducted in order to evaluate the efficacy of L-PRF, and HA for soft tissue healing, and bone regeneration after surgical removal of mandibular third molar, and to determine which one is the best graft material for regeneration.

\section{PATIENT AND METHODS}

This study was conducted in the Department of Oral and Maxillofacial surgery, Ahram Canadian University Dental College and after obtaining Institutional Ethical Clearance. The study comprised selected patients (total 36, 20 males and 16 females) who were referred for the removal of impacted mandibular third molar including both genders.

\section{Inclusion criteria}

Healthy patients seeking extraction of impacted lower third molars aged between 18 - 35 years.

\section{Exclusion criteria}

- Patients with pericoronitis, periodontitis or periapical infection,

- Smokers and alcoholics.

- Female patients on oral contraceptives.

- Uncontrolled diabetic patients.

- Patients undergoing chemotherapy or radiotherapy.

- Those patients with incomplete follow-up were excluded from the study. 
After obtaining the history of each case, patients were clinically examined. Then, the procedure for the treatment, its complications, and follow-up period involved in the study was explained to them. Patients joined for the study signed written consent. Preoperative and postoperative panoramic $\mathrm{x}$-ray view and intraoral periapical (IOPA) radiographs were taken. The patients were randomly distributed into three groups, each consisting of 12 patients ( sample size $=12 /$ group): $\bullet$ L-PRF -treated group: Comprised patients having extraction socket filled with PRF before closure of the socket (Fig. 1). • HA-treated group: Comprised patients having an extraction socket filled with HA before closure of the socket (Fig. 2). • Control group: Involved patients having an extraction socket closed without any graft material.

\section{Surgical procedure}

Surgical removal of mandibular third molars was done under local anesthesia using the standard technique. A triangular full-thickness flap has been raised; buccal guttering was done using a surgical carbide bur. After removal of the tooth and achieving hemostasis, the socket was irrigated with normal saline. Before suturing of the mucoperiosteal flap incorporation of PRF or HA within the socket was prepared in the study groups.

\section{Postoperative monitoring and variables}

Each patient received identical postoperative antibiotics (Biomox (amoxicillin) $500 \mathrm{mg}$, Sedico Company) for 5 days, analgesics (paracetamol 500 mg, ADWIC Company) for 3 days with regular instructions. In our study, all the procedures were done comfortably under local anesthesia on an outpatient basis without any complication such as lip numbness. Patients of all groups were assessed for swelling, pain, dry socket, trismus, soft tissue healing, and radiographic (IOPA) assessment for bone healing was conducted after 2 and 6 months.

\section{Pain}

The pain was assessed using a 10-point visual analog scale (VAS), with a score of " 0 " equals "no pain" and "10" equals "very severe pain. The pain was evaluated at $1^{\text {st }}, 3^{\text {rd }}$ and $7^{\text {th }}$ day. Moreover, all the patients were asked to record the analgesics taken daily to control the postoperative pain to assess the antinociceptive property. For each participant, the appropriate score was recorded in the data sheets.

\section{Soft tissue healing}

Soft tissue healing and granulation tissue formation was assessed clinically by presence and absence of bleeding and the coverage of the bony walls of the extraction site by granulation tissue which can be graded as: 0 - no bony walls exposed, 1 - only one bony wall exposed, 2 - two bony walls exposed, 3 - three bony walls exposed, and 4 - four bony walls exposed. The granulation tissue was divided into healthy (pink and does not bleed on probing) and unhealthy granulation tissue (dark red and often bleeds on probing). Granulation tissue formation was evaluated on the $1^{\text {st }}, 3^{\text {rd }}, 7^{\text {th }}$ and $14^{\text {th }}$ day. Evaluation of soft tissue healing was also based on the standard method ${ }^{(19)} \bullet$ Criteria for dry socket assessment were based on Blum's method. ${ }^{(20)}$

\section{Facial swelling and interincisal distance:}

Evaluation of facial edema and swelling was based on the degree of postoperative cheek swelling and edema was estimated by measuring the distances from the tragus to the soft tissue pogonion and from the tragus to the angle of the mouth. The swelling was evaluated on the $1^{\text {st }}, 3^{\text {rd }}$ and $7^{\text {th }}$ day postoperatively and recorded as nil, mild, moderate, and severe. ${ }^{(21)}$ Swelling measurements were taken using a millimeter ruler. Trismus measurements were taken using a calibrated digital caliper.

\section{Radiographic assessment}

The criteria of bone healing and scoring system were based on modification of the Kelley's method as described by Olufemi ${ }^{22}$ et al. Two parameters 
namely overall density score and trabecular pattern score were assessed.

\section{Overall density score}

- 3 - Marked increase in radiographic density reaching normal limits.

- 2 - Moderate increase in radiographic density.

- 1 - Mild increase in radiographic density.

- $\quad 0$ - Nil increase in radiographic density.

\section{Trabecular pattern score}

- 3 - All trabeculae substantially coarse.

- 2 - Mostly coarse and some fine trabeculae.

- 1 - Delicate, finely meshed trabeculae.

- 0 - Granular, nearly homogenous patterns; individual trabeculae essentially absent

\section{Method of preparation of platelet-rich fibrin}

PRF preparation was performed according to Dohan ${ }^{(23)}$ as 2 tubes of $10 \mathrm{ml}$ obtained from basilic or cephalic vein in an antecubital fossa. The blood was taken without anticoagulant in the plastic tubes. The blood collection was performed quickly, and the tube was immediately centrifuged at $2700 \mathrm{rpm}$ for 12 minutes (this speed is a modification of Dohan method) using a table centrifuge (gematokritny,
Centrifuge medical laboratory SH120-1S, Shanghai Medical Instruments, China). A fibrin clot was formed in the middle part, acellular plasma present in the upper part of the tube, and the red corpuscles in the bottom part. After centrifugation, the L-PRF clot was removed from the tube using sterile tweezers or artery forceps, and separated from the RBC base using scissors. The separated PRF was placed into the socket and stabilized with the help of suturing (Fig.1).

\section{Bone Graft}

The graft material used was Hypro-Oss (Bioimplon $\mathrm{GmbH}$, Biotech Innovation Pioneers, Friedrich-List-Str. 27, Germany). Hypro-Oss used in this study is a natural bovine bone substitution material for reconstruction of bone defects. Each granule consists of $30 \%$ Atelo-Collagen Type I and $70 \%$ hydroxyapatite (Figure 2).

\section{STATISTICAL ANALYSIS:}

Data from the three groups were collected, tabulated and statistically analyzed using the SPSS statistical package. The data were summarized as means and standard deviations for continuous outcomes (pain, swelling, mouth opening, bone healing index and analgesics intake). ANOVA test was used to compare the mean values of the three

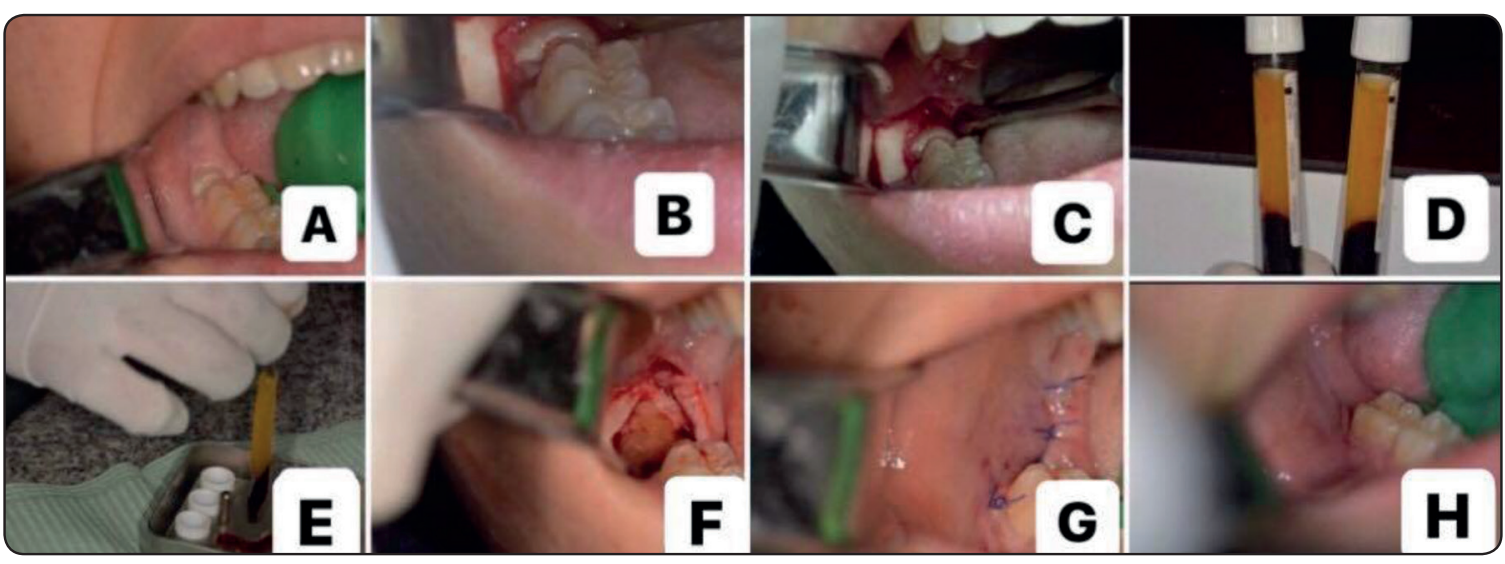

Fig. (1): A. Preoperative photograph B. Mucoperiosteal flap reflection C. Buccal bone guttering D. L- PRF in centrifugation tube E. L-PRF separation F. L-PRF placement G. suturing H. 2 weeks postop. Photograph showing soft tissue healing. 


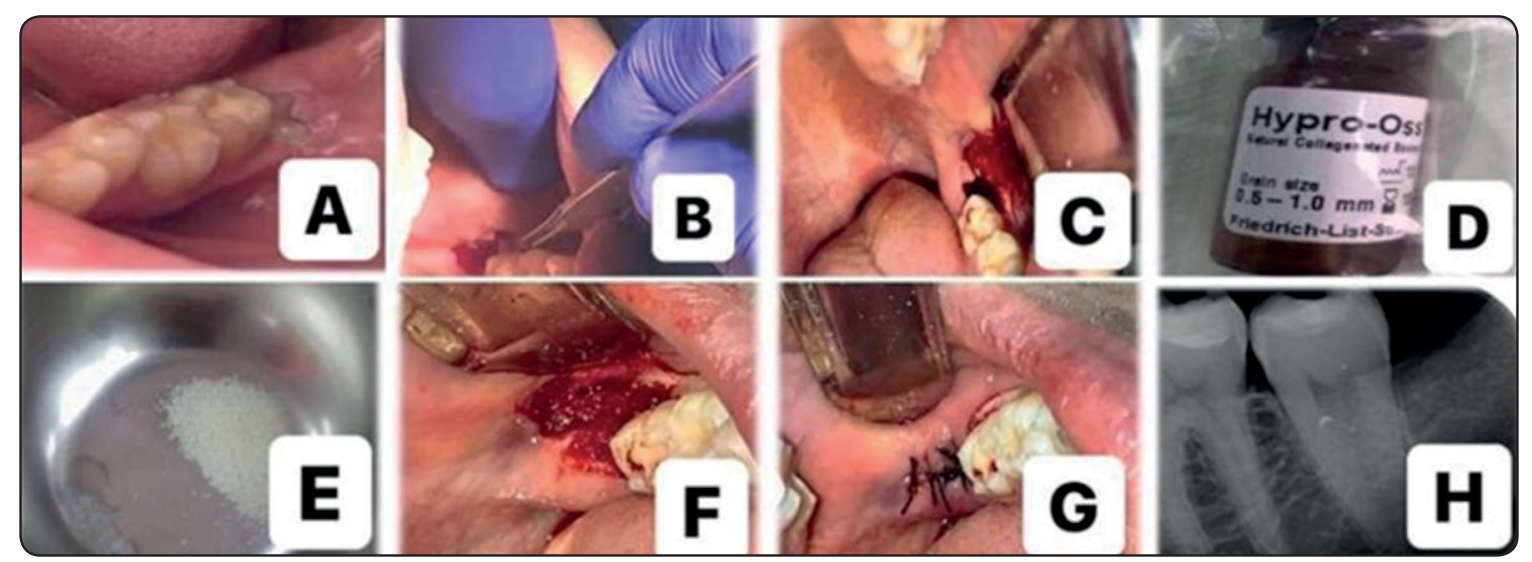

Fig. (2): A. preoperative photograph B. flab incision C. Flap reflection and buccal bone guttering D \&E. Hypro-Oss bone graft F. Hypro-Oss (HA) placement G. Suturing h. 2 months Postoperative radiograph

groups and repeated measures. ANOVA was used to evaluate the change by time in each group. The data were summarized frequency for qualitative data (Postoperative pain, swelling and edema, and exposed bony wall scores) Chi-square test used to compare the mean values of the three groups. The level of significance was set at 5\% for all statistical analyses and confidence interval at 95\% (95\% CI). The level of significance was concluded at $P<0.05$.

\section{RESULTS}

Thirty-six patients were included in the study and randomly divided into three groups: control, L-PRF, and HA groups. Each group had 12 patients. Of these 36 patients included in the study, 20 were males, and 16 were females. The age of patients in our study was a minimum 18 years and maximum 35 years (mean: 29; standard deviation [SD] 6). The mean age of patients in years $( \pm \mathrm{SD})$ in control, L-PRF, and HA groups were $29 \pm 6,28 \pm 6$, and 26 \pm 4 respectively.

The intensity of pain and swelling in these different groups was scored on the $1^{\text {st }}, 3^{\text {rd }}$ and 7 th day. The results represented in Table 2 and 3 shows a reduction in the intensity of pain along with reduced swelling in all the groups from day 1, though the maximum reduction of pain, and swelling being in PRF patients $(P<0.0001)$ (Table 1,2). Three patients were reported to have the presence of dry sockets on the $3^{\text {rd }}$ day postoperatively ( 2 control cases and 1

TABLE (1): Comparison of pain scores index of patients

\begin{tabular}{|c|c|c|c|c|c|c|c|}
\hline & \multicolumn{6}{|c|}{ Group } & \multirow{3}{*}{$\mathrm{P}$ value } \\
\hline & \multicolumn{2}{|c|}{ L-PRF } & \multicolumn{2}{|r|}{ HA } & \multicolumn{2}{|c|}{ Control } & \\
\hline & Mean & Std. Deviation & Mean & Std. Deviation & Mean & Std. Deviation & \\
\hline 1 day & 1.5833 & 0.51493 & 2.75 & 0.75378 & 5.5833 & 1.08362 & $<0.0001 *$ \\
\hline 3 days & 0.8333 & 0.71774 & 1.75 & 0.75378 & 4.1667 & 1.11464 & $<0.0001 *$ \\
\hline 7 days & 0.1667 & 0.38925 & 0.75 & 0.75378 & 2.3333 & 0.65134 & $<0.0001 *$ \\
\hline$P$ value & \multicolumn{2}{|c|}{$<0.0001 *$} & \multicolumn{2}{|c|}{$<0.001 *$} & \multicolumn{2}{|c|}{$<0.001 *$} & \\
\hline
\end{tabular}


HA case). The soft tissue healing scores were also significantly higher in L-PRF treated group [Table 4, 5]. Radiographic assessment of bone healing overall density and trabecular pattern revealed an increased score in all the groups at 2 and 6 months intervals of the healing period [Table 6], significantly higher score $(p<0.012,<0.0001,<0.0001,<0.0001)$ being in the HA-treated group. Table 7

\section{Pain score}

Three groups showed a statistically significant decrease in pain scores (VAS values) after 1,3, and 7 days. However, there is statistically significantly less pain for L-PRF group compared to other groups.

\section{Postoperative facial swelling and edema}

Three groups showed statistically significant improvement in postoperative facial swelling and edema after 1, 3, and 7 days. However, there is statistically significant more improvement for L-PRF group compared to other groups

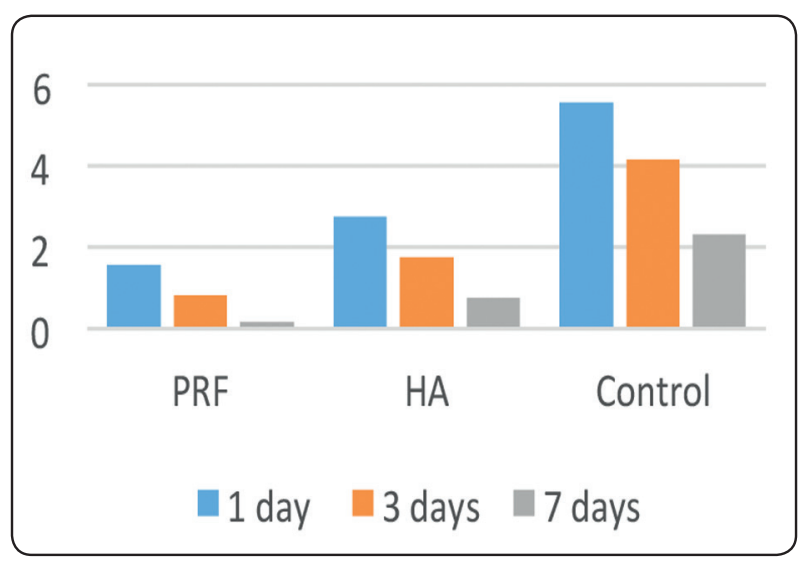

Fig. (3): Comparison of pain scores index of patients

TABLE (2): Comparison of swelling scores of patients

\begin{tabular}{|c|c|c|c|c|c|c|c|c|}
\hline & & \multicolumn{6}{|c|}{ Group } & \multirow{3}{*}{$\mathrm{P}$ value } \\
\hline & & \multicolumn{2}{|c|}{ L-PRF } & \multicolumn{2}{|c|}{ HA } & \multicolumn{2}{|c|}{ Control } & \\
\hline & & Count & $\%$ & Count & $\%$ & Count & $\%$ & \\
\hline \multirow{4}{*}{1 day } & Nil & 0 & $.0 \%$ & 0 & $.0 \%$ & 0 & $.0 \%$ & \multirow[t]{4}{*}{$<0.0001^{*}$} \\
\hline & Mild & 9 & $75.0 \%$ & 0 & $.0 \%$ & 0 & $.0 \%$ & \\
\hline & Moderate & 3 & $25.0 \%$ & 3 & $25.0 \%$ & 4 & $33.3 \%$ & \\
\hline & Severe & 0 & $.0 \%$ & 9 & $75.0 \%$ & 8 & $66.7 \%$ & \\
\hline \multirow{4}{*}{3 days } & Nil & 9 & $75.0 \%$ & 0 & $.0 \%$ & 0 & $.0 \%$ & \multirow[t]{4}{*}{$<0.0001 *$} \\
\hline & Mild & 3 & $25.0 \%$ & 3 & $25.0 \%$ & 3 & $25.0 \%$ & \\
\hline & Moderate & 0 & $.0 \%$ & 9 & $75.0 \%$ & 7 & $58.3 \%$ & \\
\hline & Severe & 0 & $.0 \%$ & 0 & $.0 \%$ & 2 & $16.7 \%$ & \\
\hline \multirow{4}{*}{7 days } & Nil & 12 & $100.0 \%$ & 5 & $41.7 \%$ & 5 & $41.7 \%$ & \multirow[t]{4}{*}{$0.011 *$} \\
\hline & Mild & 0 & $.0 \%$ & 6 & $50.0 \%$ & 7 & $58.3 \%$ & \\
\hline & Moderate & 0 & $.0 \%$ & 1 & $8.3 \%$ & 0 & $.0 \%$ & \\
\hline & Severe & 0 & $.0 \%$ & 0 & $.0 \%$ & 0 & $.0 \%$ & \\
\hline$P$ value & & \multicolumn{2}{|c|}{$<0.0001 *$} & \multicolumn{2}{|c|}{$<0.001 *$} & \multicolumn{2}{|c|}{$<0.001 *$} & \\
\hline
\end{tabular}

$* P<0.05$ mean statistically significant differences 


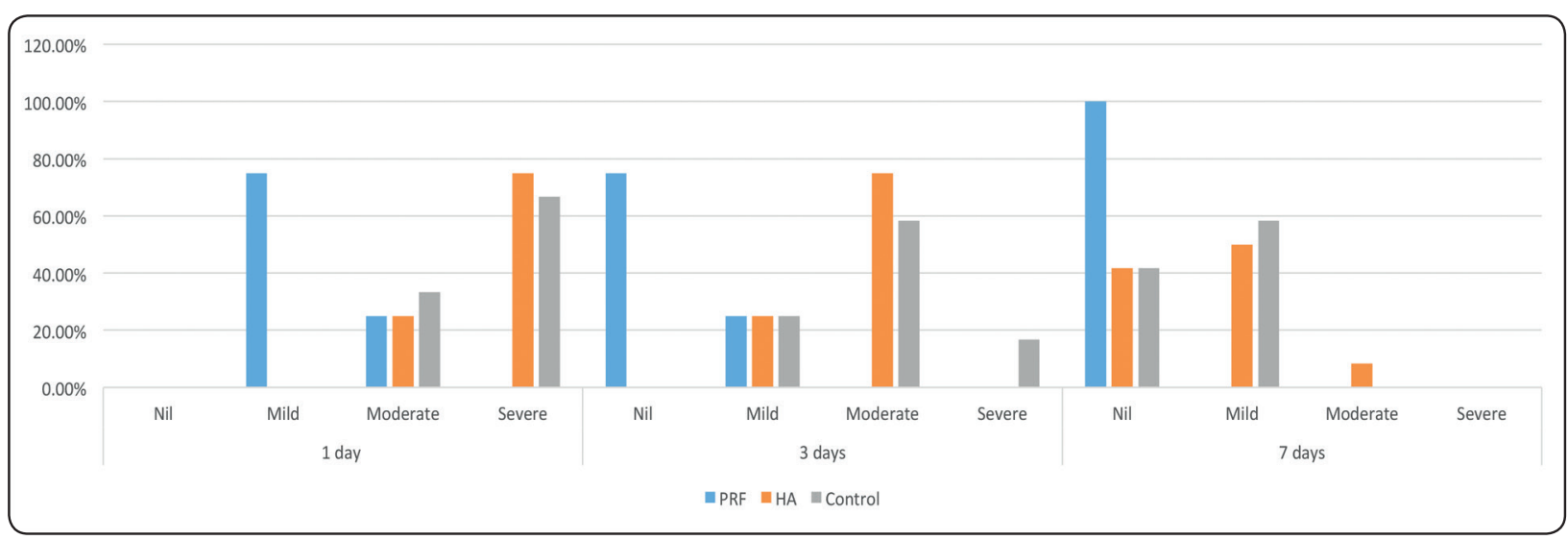

Fig. (4): Comparison of swelling scores index of patients

\section{Maximum interincisal distance}

Three groups showed a statistically significant increase in mouth opening after 1, 3, and 7 days. However, at $7^{\text {th }}$ day there is statistically significant more improvement for L-PRF group compared to other groups.

\section{Soft tissue healing score}

Three groups showed statistically significant improvement in Soft Tissue healing score after 1, 3 , and 7 days. However, at first and $7^{\text {th }}$ days there is statistically significant more improvement for L-PRF group compared to other groups

\section{Exposed bony socket walls score}

Regarding Exposed bony socket walls score at first and $7^{\text {th }}$ days there are statistically significant more improvement for L-PRF group compared to other groups

\section{Bone healing index of patients}

The HA group showed statistically significant more improvements in the overall density score and trabecular pattern score when compared to other groups.

\section{Analgesics intake}

Regarding analgesic intake, from first to the fourth day there was statistically significant less analgesic taken by the patients in the L-PRF group. However, there were no statistically significant differences between the three groups after that

TABLE (3): Evaluation of maximum inter- incisal distance (TRISMUS)

\begin{tabular}{|c|c|c|c|c|c|c|c|}
\hline & \multicolumn{6}{|c|}{ Group } & \multirow{3}{*}{$\mathrm{P}$ value } \\
\hline & \multicolumn{2}{|c|}{ L-PRF } & \multicolumn{2}{|c|}{ HA } & \multicolumn{2}{|c|}{ Control } & \\
\hline & Mean & Std. Deviation & Mean & Std. Deviation & Mean & Std. Deviation & \\
\hline 1 day & 35.0833 & 3.47611 & 32.8333 & 2.58785 & 32.8333 & 2.58785 & 0.06 \\
\hline 3 days & 39.75 & 2.49089 & 37.5 & 2.67989 & 37.5 & 2.67989 & 0.1 \\
\hline 7 days & 45.4167 & 2.84312 & 41.1667 & 2.16725 & 41.1667 & 2.16725 & $<0.0001 *$ \\
\hline$P$ value & \multicolumn{2}{|c|}{$<0.0001 *$} & \multicolumn{2}{|c|}{$<0.001 *$} & \multicolumn{2}{|c|}{$<0.001 *$} & \\
\hline
\end{tabular}

$* P<0.05$ means statistically significant differences 
TABLE (4): Comparison of the degree of inflammation of soft tissue of three groups

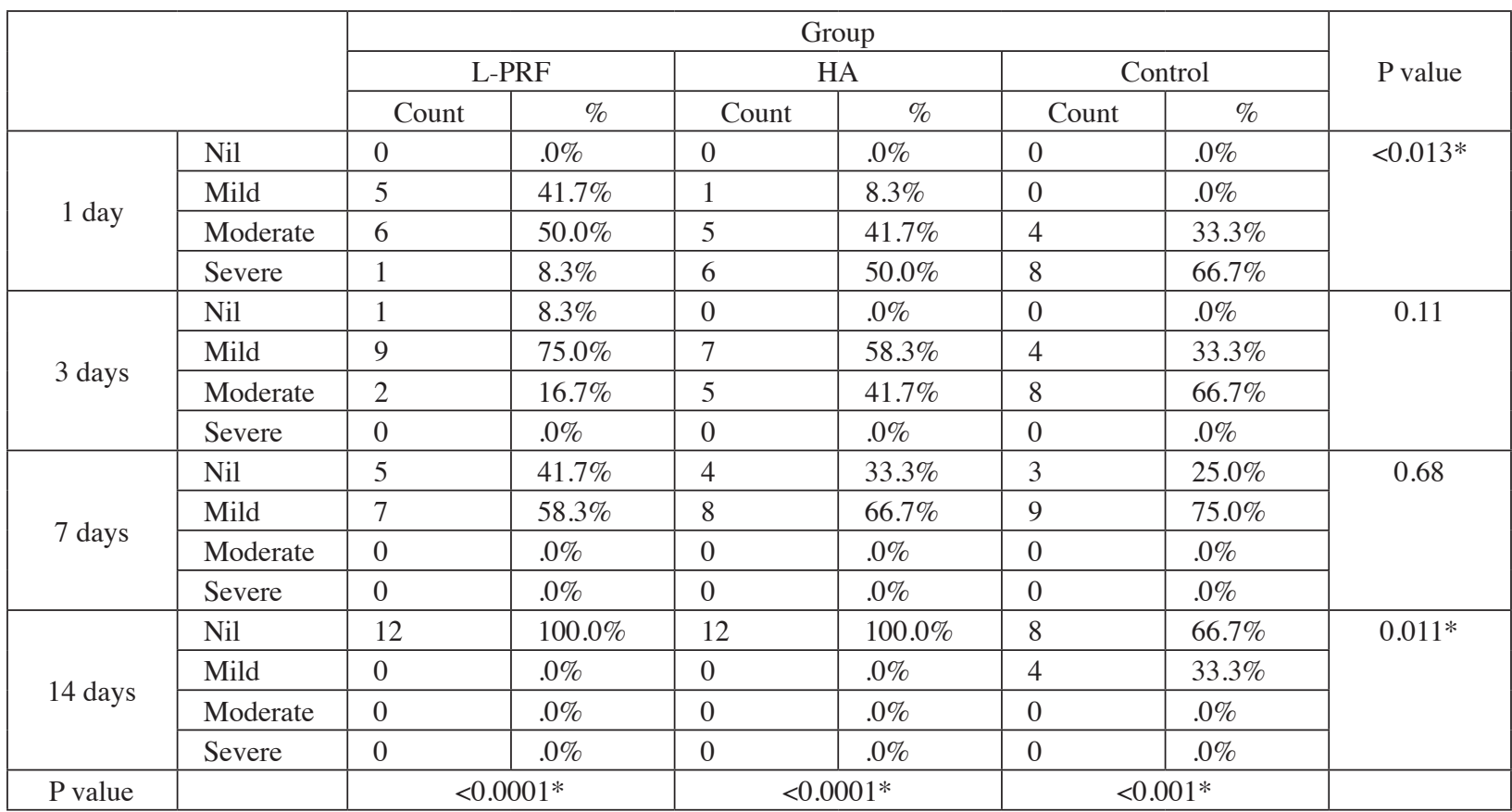

$* P<0.05$ means statistically significant differences

TABLE (5): Comparison of exposed bony walls index score of three groups

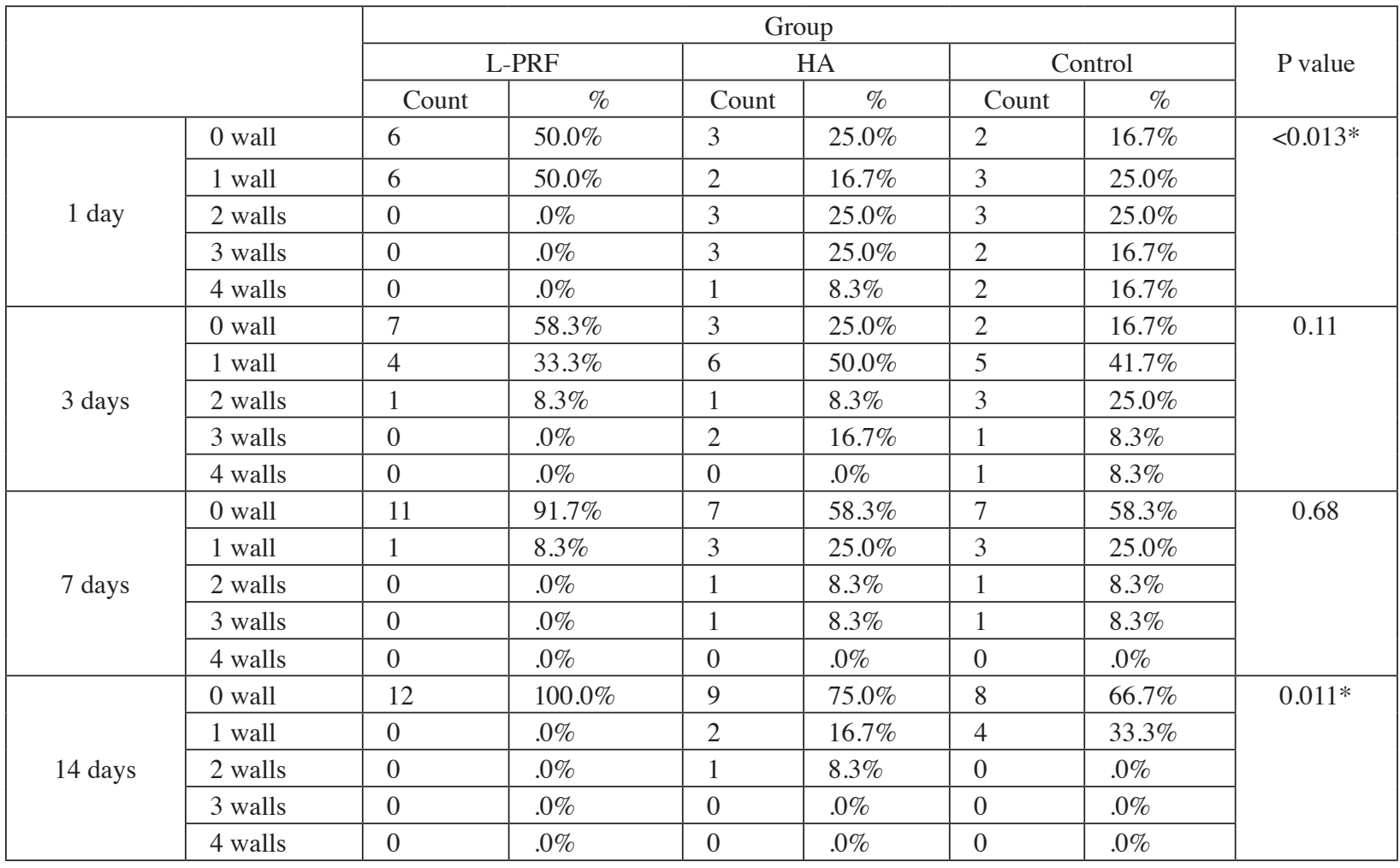


TABLE (6): Comparison of bone healing index of patients

\begin{tabular}{|c|c|c|c|c|c|}
\hline & & & Mean & Std. Deviation & $\mathrm{P}$ value \\
\hline \multirow{6}{*}{ Overall density score } & \multirow{3}{*}{2 months } & L-PRF & 0.8333 & 0.71774 & \multirow{3}{*}{$0.012 *$} \\
\hline & & HA & 1.5 & 0.6742 & \\
\hline & & Control & 0.6667 & 0.65134 & \\
\hline & \multirow{3}{*}{6 months } & PRF & 1.9167 & 0.66856 & \multirow{3}{*}{$<0.0001 *$} \\
\hline & & HA & 2.5833 & 0.66856 & \\
\hline & & Control & 1.25 & 0.75378 & \\
\hline \multirow{6}{*}{ Trabecular pattern score } & \multirow{3}{*}{2 months } & L-PRF & 1.1667 & 0.71774 & \multirow{3}{*}{$0.004 *$} \\
\hline & & HA & 1.4167 & 0.66856 & \\
\hline & & Control & 0.5 & 0.52223 & \\
\hline & \multirow{3}{*}{6 months } & L-PRF & 2.0833 & 0.66856 & \multirow{3}{*}{$<0.0001^{*}$} \\
\hline & & HA & 2.4167 & 0.66856 & \\
\hline & & Control & 1.3333 & 0.49237 & \\
\hline
\end{tabular}

$* P<0.05$ mean statistically significant differences

TABLE (7): Daily and total of analgesics consumption of three groups

\begin{tabular}{|c|c|c|c|c|c|c|c|}
\hline & \multicolumn{6}{|c|}{ Group } & \multirow{3}{*}{$P$ value } \\
\hline & \multicolumn{2}{|c|}{ L-PRF } & \multicolumn{2}{|c|}{ HA } & \multicolumn{2}{|c|}{ Control } & \\
\hline & Mean & $\begin{array}{c}\text { Std. } \\
\text { Deviation }\end{array}$ & Mean & $\begin{array}{c}\text { Std. } \\
\text { Deviation }\end{array}$ & Mean & $\begin{array}{c}\text { Std. } \\
\text { Deviation }\end{array}$ & \\
\hline Day 1 & 1.5833 & 0.79296 & 2.75 & 0.62158 & 3.5833 & 0.90034 & $<0.0001^{*}$ \\
\hline Day 2 & 1 & 0.60302 & 1.9167 & 0.66856 & 2.5833 & 0.66856 & $<0.0001^{*}$ \\
\hline Day 3 & 0.5833 & 0.51493 & 1.1667 & 0.38925 & 1.6667 & 0.65134 & $<0.0001 *$ \\
\hline Day 4 & 0.3333 & 0.49237 & 0.5 & 0.52223 & 0.9167 & 0.51493 & $0.02 *$ \\
\hline Day 5 & 0 & 0 & 0.25 & 0.45227 & 0.3333 & 0.49237 & 0.11 \\
\hline Day 6 & 0 & 0 & 0 & 0 & 0 & 0 & - \\
\hline Day 7 & 0 & 0 & 0 & 0 & 0 & 0 & - \\
\hline
\end{tabular}

$* P<0.05$ mean statistically significant differences

\section{DISCUSSION}

New therapies and biomaterials have been utilized to improve patient outcomes in terms of soft and bone tissue regeneration. The clinical effects (pain and facial swelling, trismus, soft tissue healing) and radiographic effects (trabecular pattern and bone density) were compared, in order to have an idea about the effect of graft material on the healing socket. Our results indicate the positive effect of L-PRF on tissue healing and inflammation that coincide with the antinociceptive property of
PRF (Table 1,7) (Fig.3). While comparing the facial swelling, our results showed less facial enlargement for the PRF group with an enhancement in mouth opening (Table 2,3) (Fig.4). All these results might due to effectively trigger stimulation of L-PRF on osseous and soft tissue regeneration, leading to reduced inflammation, pain and other side effects. PRF seems to be efficient on postoperative pain, swelling, and trismus.

However, there are several clinical trials to support the positive effect of autologous materials 
in soft tissue healing and bone regeneration and increasing bone density in comparison with other types of grafts. The results of the present study are in accordance with Al-Hamed, et al ${ }^{(10)}$, Kumar et $\mathrm{al}^{(24)}$ and Bilginaylar and Uyanik results ${ }^{(25)}$. These researches showed a significant effect of L-PRF on postoperative swelling and pain perception as it showed less pain in comparison with HA. It has been claimed that its effect is due to the interaction between a fibrin matrix, platelets, growth factors, leukocytes, and stem cells. These active components of L-PRF are involved in cell proliferation and differentiation, extracellular matrix synthesis, chemotaxis and angiogenesis (neovascularization). The fibrin network acts as a barrier against soft tissue invasion to the extraction socket during the healing period and the matrix which has intense growth factors and cytokines that are essential for better healing of both soft and hard tissue.

The present study showed more improvement of soft tissue healing with less inflammation and bleeding score for L-PRF group. Also, there is more improvement of exposed bony socket walls score for L-PRF group (Table 4, 5). These results suggest that the use of L-PRF as a grafting material may improve the clinical healing by neovascularization and epithelial coverage of the extraction socket that could be achieved by aid of L-PRF This perhaps due to copious amount of growth factors; as these factors play an essential role in the reconstitution of tissue, and re-establishment of the vascularity. More improvement of soft tissue healing with L-PRF might be attributed to the continuous release of growth factors for at least seven, and up to 28 days, which means the period of remodeling .Sockets showed better healing, and their bony walls was covered of healthy granulation tissue on the 2nd week postoperatively, after being treated with L-PRF leading prevention of dry socket [Table 5].

The results of our research show that the L-PRF enhance the bone density with time, but it is prolonged in comparison with the HA (Table 6). According to Wang and Tao, L-PRF had an effect on proliferation and differentiation of osteoblasts; this was shown histologically in the rat used in their study, this was significantly showed radiographically in our study. In contrast to our study Faot., et $a l^{(26)}$ found that the L-PRF did not enhance bone tissue repair in rabbit tibia during 4 weeks experiment but our results are similar to Kim., et al (27) that they found that the addition of L-PRF, in the bone defect in the rabbit skull, increased the bone formation at the 6th week The positive results of PRF could be attributed to mitogenic response in the periosteum under the influence of growth factors released from the platelets entangled within fibrin matrix.

Epithelial coverage of the extraction socket can be achieved with the support of L-PRF as a filling material in extraction socket; that clinically confirmed with neovascularization and this suggests that use of the L-PRF as a grafting material for socket that might improve the clinical healing. This perhaps due to copious amount of growth factors such as platelet-derived growth factor (PDGF), transforming growth factor beta (TGF-b), epidermal growth factor (EGF), liberated from L-PRF network; these factors play an essential role in reconstitution tissue, covering of the wound, and re-establishing the vascular integrity. L-PRF has a slow continuous release of essential growth factors for at least seven and up to 28 days, which means the L- PRF activates its background for a significant period. Thus it provides a great potential during wound healing. HA materials have been utilized in medicine and dentistry because of their proven biocompatibility and capability of promoting wound healing, it is beneficial to use HA placement which is effective in inhibiting epithelial migration.

Our radiographic results revealed better bone healing at HA site than other sites, suggesting that HA has an excellent bone conductive property. Porous HA permits the growth of osteogenic cells 
from existing bone surfaces into adjacent bone graft. L-PRF had an effect on proliferation and differentiation of osteoblasts. Studies have shown that HA is well tolerated by the surrounding uninflamed tissues and is suitable for application in humans. The present result from the assessment of dry socket supports a previous report indicating that PRF and HA can be an effective preventive factor for dry socket (results are statistically significant Table 6). It was recently hypothesized that by reducing centrifugation $\mathrm{G}$-force, a total increase in leukocyte numbers would remain in the top third layer of platelet concentrate tubes where PRF are collected so we used the speed of $2700 \mathrm{rpm}$ instead of $3000 \mathrm{rpm}$. L-PRF is mostly preferred over other concentrates because it releases the growth factors at a sustained rate over a longer period, thus optimizing wound healing.

All the materials used in this study were found to be biocompatible with no foreign body reaction. One of the disadvantages of PRF over HA is that former preparation is inconvenient procedure; hence preparations need patient's blood collection while HA is readily available and can be placed immediately. The use of L-PRF is cost effective for the patients compared to HA graft. However, long-term follow and a wide scale of the patient are required for assessment of the efficacy of these graft materials.

\section{CONCLUSION}

The use of L-PRF is beneficial for patients as it could be used as a graft like the HA. It could enhance the soft and hard tissue repair. It is easy to be prepared, simple and cost-effective. Regeneration of bone after third molar surgery in HA is much better as compared to the control and L-PRF -treated patients postoperatively, further clinical trials with follow-up of longer duration with larger sample size need to be done to get a more decisive result.

\section{REFERENCES}

1. Olczyk, P. Mencner, $Ł$ and Komosinska-Vassev, K.: The role of the extracellular matrix components in cutaneous wound healing. BioMed Research International: 74:75-84, 2014.

2. Walter CJ1, Dumville JC, Sharp CA and Page T. Systematic review and meta-analysis of wound dressings in the prevention of surgical-site infections in surgical wounds healing by primary intention. British Journal of Surgery 99: 1185-1194, 2012.

3. Zhang Y, Zheng R, Minhua SH, LuanjunT, Weiqin H, Lei $\mathrm{W}$, and Yuanliang $\mathrm{H}$ : Clinical effect of platelet-rich fibrin on the preservation of the alveolar ridge following tooth extraction. Experimental and Therapeutic Medicine 15: 2277-2286, 2018.

4. Alzahrani A, Murraiky A, and Shafik S: Influence of Platelet Rich Fibrin on Post-extraction Socket Healing: A Clinical and Radiographic Study. Saudi Dental Journal 29:149-155, 2017.

5. Gassling VL, Açil Y, Springer IN, Hubert N, and Wiltfang $\mathrm{J}$ : Platelet-rich plasma and platelet-rich fibrin in human cell culture. Oral Surg Oral Medicine oral pathology Oral Radiology and Endodontology 108.1:4-55, 2009.

6. Naik B, Karunakar P, Jayadev M, and Marshal V R: Role of Platelet-rich fibrin in wound healing: A critical review. Journal of Conservative Dentistry 16.4:284-293, 2013.

7. Hartshorne $\mathbf{J}$ and Gluckman $\mathrm{H}$ : A comprehensive clinical review of Platelet Rich Fibrin (PRF) and its role in promoting tissue healing and regeneration in dentistry. Part II: preparation, optimization, handling and application, benefits and limitations of PRF. International Dentistry 6: 34-48, 2016.

8. Madhan G and Madhumati S: Comparison of Ability of Platelet-rich Fibrin Vs Colla Plug in maintaining the Buccal Bone Height of Sockets following Extractions in 20 Patients. Journal of Health Sciences and Research 8.1: 1-6, 2017.

9. Yamamoto K, Novelli M D, Correa L, de Sousa S, and Luz J: Evaluation of the Effect of Platelet-Rich Plasma on Alveolar Wound Healing in Rats. International Journal of Morphology 35.1: 251-258, 2017.

10. Al-Hamed FS, Tawfik MA, Abdelfadil E, Al-Saleh MAQ: Clinical effects of platelet-rich fibrin (PRF) following surgical extraction of lower third molar. The Saudi Journal for Dental Research 8: 19-25, 2017. 
11. Gaetano M, Francesco R, Mariano T Alessandro di L, and Gilberto S: Influence of Leukocyte and Platelet-Rich Fibrin (L-PRF) in the Healing of Simple Post extraction Sockets: A Split-Mouth Study. BioMed Research International: 10.1155-1161, 2015.

12. Ross R, Glomset J, Kariya B, and Harker L: A platelet dependent serum factor that stimulates the proliferation of arterial smooth muscle cells in vitro. Proc Natl Acad Sci U S A; 71:1207-1210, 1974.

13. Choukroun J, Diss A, Simonpieri A, Girard MO, Schoeffler C, and Dohan SL: Platelet rich fibrin (PRF): A second generation platelet concentrate. Part V: Histologic evaluations of PRF effects on bone allograft maturation in sinus lift. Oral Surg Oral Med Oral Pathol Oral Radiol Endod. 101:299-303, 2006.

14. Gassling V, Douglas T, Warnke PH, Açil Y, Wiltfang J, Becker ST: Platelet rich fibrin membranes as scaffolds for periosteal tissue engineering. Clin Oral Implants Res; 21:543, 2010.

15. Anitua E, S nchez M, Nurden AT, Nurden P, Orive G, and Anda I: New insights into and novel applications for platelet rich fibrin therapies. Trends Biotechnol; 24:227-234, 2006.

16. Nandi SK, Kundu B, Ghosh SK, De DK, Basu D. Efficacy of nano hydroxyapatite prepared by an aqueous solution combustion technique in healing bone defects of a goat. $\mathrm{J}$ Vet Sci; 9:183-191, 2008.

17. Minami M, Takechi M, Ohta K, Ohta A, Ninomiya Y, Takamoto M, Fukui A, Tada M, and Kamata N: Bone formation and osseointegration with titanium implant using granular and block type porous hydroxyapatite ceramics (IPCHA). Dent Mater J; 32:753-760, 2013.

18. Moreira Gonzalez A, Jackson IT, Miyawaki T, DiNick V, Yavuzer R: Augmentation of the craniomaxillofacial region using porous hydroxyapatite granules. Plast Reconstr Surg; 111:1808-1817, 2003.

19. Landry RG, Turnbull RS, and Howley T: Effectiveness of benzydamine $\mathrm{HCl}$ in the treatment of periodontal post-surgical patients. Res Clin Forums, 10:105-118, 1988.
20. Blum IR: Contemporary views on dry socket (alveolar osteitis): A clinical appraisal of standardization, aetiopathogenesis, and management: A critical review. Int J Oral Maxillofac Surg; 31:309-317, 2002.

21. Mansuri S, Mujeeb A, Hussain SA, Hussain MA: Mandibular third molar impactions in male adults: Relationship of operative time and types of impaction on inflammatory complications. J Int Oral Health; 6:9-15, 2014.

22. Olufemi K, Ogundipe, Vincent I Ugboko, Folusho J Owotade: Can autologous platelet rich plasma gel enhance healing after surgical extraction of mandibular third molars? J Oral Maxillofac Surg; 69: 2305-2310, 2011.

23. Dohan Ehrenfest DM: How to optimize the preparation of leukocyte- and platelet-rich fibrin (L-PRF, Choukroun's technique) clots and membranes: Introducing the PRF Box. Oral Surg Oral Med Oral Pathol Oral Radiol Endod 110: 275-280, 2010.

24. Kumar N, Parasad K, Ramanujam L, K R, Dexith j, and Chauhan A: Evaluation of treatment outcome after impacted mandibular third molar surgery with the use of autologous platelet-rich fibrin: a randomized controlled clinical study. Journal of Oral and Maxillofacial Surgery; 73:1042$1049,2015$.

25. Bilginaylar K and Uyanik LO: Evaluation of the effects of platelet-rich fibrin and piezosurgery on outcomes after removal of impacted mandibular third molars. Br J Oral Maxillofac Surg; 54:629-33, 2016.

26. Faot F, Deprez S, Vandamme K, Camargos GV, Pinto N, Wouters J, van den Oord J, Quirynen M, and Duyck J: The effect of L-PRF membranes on bone healing in rabbit tibiae bone defects: micro-CT and biomarker results. Sci Rep 7: 46452, 2017.

27. Kim TH, Sándor GK, and Kim YD: Comparison of platelet-rich plasma (PRP), platelet-rich fibrin (PRF), and concentrated growth factor (CGF) in rabbit-skull defect healing. Arch Oral Biol.; 59(5):550-8, 2014. 